\title{
Tris(pentafluoroethyl)trifluorophosphate-basd ionic liquids as advantageous solid-phase micro-extraction coatings for the extraction of organophosphate esters in environmental waters ${ }^{\text {is }}$
}

\author{
Fengqiong Shi ${ }^{\mathrm{a}, \mathrm{b}}$, Jingfu Liu ${ }^{\mathrm{a}, \mathrm{b}, *}$, Kang Liang ${ }^{\mathrm{a}, \mathrm{b}}$, Rui Liu ${ }^{\mathrm{a}}$ \\ a State Key Laboratory of Environmental and Ecotoxicology, Research Center for Eco-Environmental Sciences, Chinese Academy of Sciences, Beijing 100085, \\ China \\ ${ }^{\mathrm{b}}$ University of Chinese Academy of Sciences, Beijing 100049, China
}

\section{A R T I C L E I N F O}

\section{Article history:}

Received 2 March 2016

Received in revised form 7 April 2016

Accepted 7 April 2016

Available online 11 April 2016

\section{Keywords:}

Organophosphate esters (OPEs)

Ionic liquid

Tris(pentafluoroethyl)trifluorophosphate

Solid-phase microextraction (SPME)

Gas chromatography-mass spectrometry

(GC-MS)

\begin{abstract}
A B S T R A C T
Ionic liquids (ILs) containing the tris(pentafluoroethyl)trifluorophosphate [FAP] anion and various cations have great potential in sample preparation because of their excellent hydrophobicity, thermostability and low hydrolysity. In the present study, a [FAP]-based IL, 1-hexyl-3-methylimidazolium tris (pentafluoroethyl) trifluoro phosphate ([HMIM][FAP]), was used as coatings of solid-phase microextraction (SPME) for extracting organophosphate esters (OPEs) from environmental water samples. This SPME fiber was fabricated by coating a stainless steel wire substrate with [HMIM][FAP] via a simple direct dip-coating approach, and the extraction was conducted by the direct immersion solid phase microextraction. Coupling to gas chromatography mass spectrometry (GC-MS), the developed SPME method exhibited excellent selectivity and sensitivity towards the extraction of 11 OPEs from aqueous samples. Satisfactory linearity $\left(R^{2} \geq 0.99\right)$ of the calibration curves was obtained over the range of $0.05-50.0 \mathrm{ng} \mathrm{mL}^{-1}$ with the limits of detection (LODs, $\mathrm{S} / \mathrm{N}=3$ ) and limits of quantification (LOQs, $\mathrm{S} / \mathrm{N}=10$ ) ranged from 0.13-7.40 ng L $^{-1}$ and $0.50-24.0 \mathrm{ng} \mathrm{L}^{-1}$, respectively. The proposed SPME method showed excellent extraction efficiency to OPEs with enrichment factors in the range of 168-2603, and acceptable reproducibility with relative standard deviations (RSDs) $\leq 15 \%$ for single fiber $(n=7)$ and $\leq 16 \%$ for fiber-to-fiber $(n=3 \times 3)$ at a concentration level of $0.5 \mathrm{ng} \mathrm{mL}^{-1}$, respectively. The prepared IL-based fiber was successfully applied to determine eleven common used OPEs in tap water, influent and effluent of sewage treatment plant, with results are comparable to those determined by the reference (UPLC-MS/MS), and spiked recoveries in the range of $84.0-108 \%, 82.1-123 \%$ and $82.8-100 \%$, respectively.
\end{abstract}

(c) 2016 Elsevier B.V. All rights reserved.

\section{Introduction}

Organophosphate esters (OPEs) are mainly used as flameretardants, plasticizers, hydraulic fluid, antifoaming agents, lubricants, floor covering, and lacquer/paint/glue [1,2]. OPEs are regarded as high-production-volume chemicals, with a global consumption amounted to 500,000 $t$ in 2011, and the demand for OPEs is expected to increase in the near future [2]. In most cases, OPEs are directly mixed, not chemically bonded, with the original materials; therefore, they can easily be released into the surrounding environ-

\footnotetext{
Selected paper from 17th International Symposium on Advances in Extraction Technologies, 7-11 November 2015, Sun Yat-Sen University, Guangzhou, Guangdong, China.

* Corresponding author.

E-mail address: jfliu@rcees.ac.cn (J. Liu).
}

ment by abrasion and/or volatilization [2]. In fact, OPEs are already ubiquitous in various environments, as they have been detected in sewage treatment plants (STPs) [3], indoor environments [4,5], atmospheric particles [6,7], aquatic environment [2,7-9], biota $[10,11]$ and also human body fluid $[10,12]$. Moreover, some halogenated OPEs, such as tris(2-chloroethyl)phosphate (TCEP), tris(chloroisopropyl)phosphate (TCPP) and tris(1,3-dichloro-2propyl)phosphate (TDCP), are quite recalcitrant to naturally degradation or biodegradation [1,3], suggesting that they are likely to enter the aquatic environment and persistent in environment. In addition, extensive studies have showed that exposure to several OPEs pose a potential health risk for animals and humans [12-14]. The widespread usage and potential toxicities of these compounds are responsible for their increasing public concern and research attention, and it is of importance to determine OPEs in environmental waters. 
Table 1

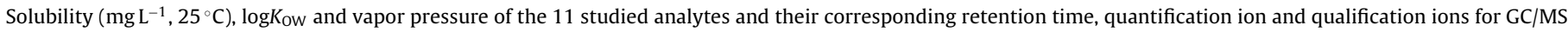
(SIM) analysis.

\begin{tabular}{|c|c|c|c|c|c|c|c|}
\hline Compound & Abbreviation & $\begin{array}{l}\text { Solubility } \\
\left(\mathrm{mg} \mathrm{L}^{-1}, 25^{\circ} \mathrm{C}\right)\end{array}$ & $\log K_{\mathrm{OW}}{ }^{\mathrm{a}}$ & $\begin{array}{l}\text { Vapor } \\
\text { pressure }^{\mathrm{a}} \\
(\mathrm{mm} \mathrm{Hg} \text {, } \\
\left.25^{\circ} \mathrm{C}\right)\end{array}$ & $\begin{array}{l}\text { Retention time } \\
\text { (min) }\end{array}$ & $\begin{array}{l}\text { Quantification } \\
\text { ion }(m / z)\end{array}$ & $\begin{array}{l}\text { Qualification } \\
\text { ions }(m / z)\end{array}$ \\
\hline Tri-n-propyl phosphate & TPrP & 827 & 2.67 & $2.9 \times 10^{-2}$ & 7.07 & 99 & $253,123,141$ \\
\hline Tri-n-butyl phosphate & TnBP & 280 & 4.00 & $1.1 \times 10^{-3}$ & 8.21 & 99 & $155,211,125$ \\
\hline Tris(2-chloroethyl)phosphate & TCEP & $7.0 \times 10^{3}$ & 1.44 & $1.1 \times 10^{-4}$ & 8.77 & 63 & $249,143,251$ \\
\hline Tris(chloroiso-propyl)phosphate & TCPP & $1.6 \times 10^{3}$ & 2.59 & 0.75 & 8.99 & 125 & $99,277,157$ \\
\hline Tris(1,3-dichloro-2-propyl)phosphate & TDCP & 1.50 & 3.80 & $7.4 \times 10^{-8}$ & 12.93 & 75 & $99,191,209$ \\
\hline Tris(2-butoxyethyl)phosphate & TBEP & $1.2 \times 10^{3}$ & 3.65 & $2.1 \times 10^{-7}$ & 13.51 & 57 & $85,125,199$ \\
\hline Triphenyl phosphate & TPhP & 1.90 & 4.59 & $1.2 \times 10^{-6}$ & 13.63 & 326 & $325,77,170$ \\
\hline 2-Ethylhexyldiphenyl phosphate & EHDPP & 1.90 & 5.73 & $6.5 \times 10^{-7}$ & 13.85 & 251 & $94,250,362$ \\
\hline Tris(2-ethylhexyl)phosphate & TEHP & 0.60 & 4.22 & $2.0 \times 10^{-6}$ & 14.15 & 99 & $113,211,57$ \\
\hline Cresyl diphenyl phosphate & CDiPP & 0.24 & 4.51 & $4.7 \times 10^{-6}$ & 14.50 & 340 & $339,77,341$ \\
\hline Tricresyl phosphate & $\mathrm{TCrP}$ & 0.36 & 5.11 & $1.8 \times 10^{-7}$ & 16.30 & 368 & $367,165,91$ \\
\hline
\end{tabular}

a Data taken from Ref. [40].

Due to the complex sample matrices and low contents of OPEs, sample preparation has to be performed before instrumental determination. Liquid-liquid extraction (LLE) $[2,9]$ and solid-phase extraction (SPE) [15-17] are the most commonly used techniques for concentration of OPEs from aqueous samples. Although the LLE method is a useful and traditional method for sample preparation, this technique has many disadvantages such as consumption of large volume of the toxic high-purity solvent, and tedious, time-consuming, emulsion formation, additionally, poor sensitivity for TCEP $[18,19]$. While SPE could considerably overcome the drawbacks of LLE, SPE cartridges are susceptible to plugging and expensive [20]. In addition, SPE with Oasis HLB cartridges are not suitable for analysis of tris(2-ethylhexyl) phosphate (TEHP) [15]. Solid-phase micro-extraction (SPME) is a very simple and efficient solventless sample preparation method, which integrates sampling, extraction, concentration and sample introduction into a single step $[19,21,22]$. This technique has been widely used in different fields including the analysis of environmental, food, natural products, pharmaceuticals, and forensic samples [23,24]. Although a number of commercial SPME fibers are available for the determination of some OPEs from aqueous samples [15,25], they are generally expensive, and suffered from several drawbacks such as lack of selectivity, short life span, low thermal and chemical stability, and fragility. Moreover, according to Rodríguez et al., due to the low recoveries (ca. 26.7\%), unacceptable deviations and poor repeatability, commercial SPME fibers are not suitable for analyzing tris(2-ethylhexyl) phosphate (TEHP) [15].
The unique properties of ionic liquids (ILs) like high stability, negligible vapor pressure, low melting points and moderate dissolvability of organic compounds make them ideal candidates for numerous micro-extraction approaches solvents [26-30] or sorbent coatings [31-33]. To our knowledge, however, there are only two papers on the development of IL-based SPME fibers for determination of OPEs [31,34]. Gao et al. developed an IL (1-allyl-3methylimidazolium tetrafluoroborate, [AMIM] [BF4])-based SPME fiber, coating by sol-gel technology, for extracting OPEs [34]. Although the extraction capability of the prepared coating provided comparable accuracy and efficiency with commercial SPME fiber, the coating preparation procedure is tedious and the fused-silica support fiber is fragile. More recently, a disposable IL-coated etched stainless steel (IL-ESS) fiber was prepared for analyzing OPEs [34]. The prepared fiber exhibit a higher extraction capacity than the commercial SPME fibers, but the repeated coating process had to be conducted for each extraction, which is time-consuming and laborious. Additionally, most of the commonly used OPEs are lowvolatile compounds (Table 1 ), thus choosing a direct immersion SPME mode could significantly facilitate the extraction process and improve the extraction efficiency. However, due to the relatively high water solubility of the used IL in the previous study [34], extracting OPEs were carried out in a headspace SPME (HS-SPME) mode, causing relatively low enrichment factors for analytes. A new class of ILs containing the tris(pentafluoroethyl) trisfluorophophate [FAP] anion have been shown to have remarkable hydrolytic, thermal and electrochemical stability. In comparison with the popularly used hydrophobic ILs with $\left[\mathrm{PF}_{6}\right]^{-}$anion and $\left[\mathrm{NTf}_{2}\right]^{-}$, the [FAP]-

Table 2

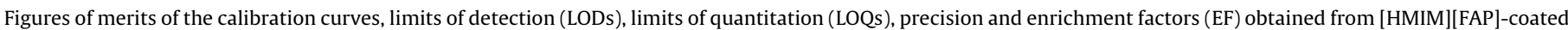
fibers in Milli-Q-purified water under the optimized conditions.

\begin{tabular}{|c|c|c|c|c|c|c|c|c|}
\hline Analyte & Regression equation & $\mathrm{R}^{2}$ & $\begin{array}{l}\text { Linear range } \\
\left(\mathrm{ng} \mathrm{mL} L^{-1}\right)\end{array}$ & $\begin{array}{l}\text { LODs } \\
\left(\mathrm{ng} \mathrm{L}^{-1}\right)\end{array}$ & $\begin{array}{l}\text { LOQs } \\
\left(\mathrm{ng} \mathrm{L}^{-1}\right)\end{array}$ & $\begin{array}{l}\text { Repeatability } \\
\text { single fiber } \\
(\mathrm{RSD}, \%, \mathrm{n}=7)\end{array}$ & $\begin{array}{l}\text { Reproducibility } \\
\text { fiber-to-fiber } \\
(\text { RSD, \%, } \\
n=3 \times 3)\end{array}$ & $\begin{array}{l}\mathrm{EF}^{\mathrm{a}} \\
(\text { mean } \pm \mathrm{SD}, \\
\mathrm{n}=5)\end{array}$ \\
\hline TPrP & $y=1.822 x+18.37$ & 0.9156 & $0.05-50.0$ & 0.70 & 2.00 & 1.2 & 11 & $168 \pm 2$ \\
\hline TnBP & $y=3193 x+2970$ & 0.9973 & $0.05-50.0$ & 0.13 & 0.50 & 2.3 & 5.5 & $267 \pm 6$ \\
\hline TCEP & $y=787.5 x+9.318$ & 0.9969 & $0.05-5.00$ & 7.40 & 24.0 & 9.1 & 11 & $268 \pm 25$ \\
\hline ТСРР & $y=780.2 x+615.1$ & 0.9952 & $0.05-5.00$ & 1.61 & 5.00 & 8.9 & 7.8 & $186 \pm 13$ \\
\hline TDCP & $y=1235 x+513$ & 0.9996 & $0.05-50.0$ & 0.43 & 1.50 & 9.9 & 11 & $515 \pm 60$ \\
\hline TBEP & $y=4956 x+3729$ & 0.9961 & $0.05-50.0$ & 0.51 & 1.70 & 3.5 & 9.0 & $370 \pm 12$ \\
\hline $\mathrm{TPhP}$ & $y=19700 x-5640$ & 0.9986 & $0.05-50.0$ & 0.30 & 1.00 & 5.8 & 9.7 & $1037 \pm 61$ \\
\hline EHDPP & $y=18930 x+4043$ & 0.9991 & $0.05-50.0$ & 0.65 & 2.00 & 4.6 & 10 & $2603 \pm 123$ \\
\hline TEHP & $y=77810 x-20680$ & 0.9975 & $0.05-50.0$ & 1.20 & 4.00 & 15 & 16 & $1465 \pm 221$ \\
\hline CDiPP & $y=4143 x+525.4$ & 0.9999 & $0.05-50.0$ & 0.33 & 1.00 & 7.2 & 7.0 & $2484 \pm 180$ \\
\hline $\mathrm{TCrP}$ & $y=12610 x-2486$ & 0.9998 & $0.05-50.0$ & 1.00 & 3.30 & 2.3 & 9.3 & $987 \pm 23$ \\
\hline
\end{tabular}

a EF was calculated by the peak area ratio of the analyte extracted by the IL-coated fiber from the water sample at $0.5 \mu \mathrm{g} \mathrm{L}^{-1}$ spiking to that detected by directly injecting $1 \mu \mathrm{L}$ of the $0.5 \mu \mathrm{g} \mathrm{L}^{-1}$ standard solution into the GC-MS system. 


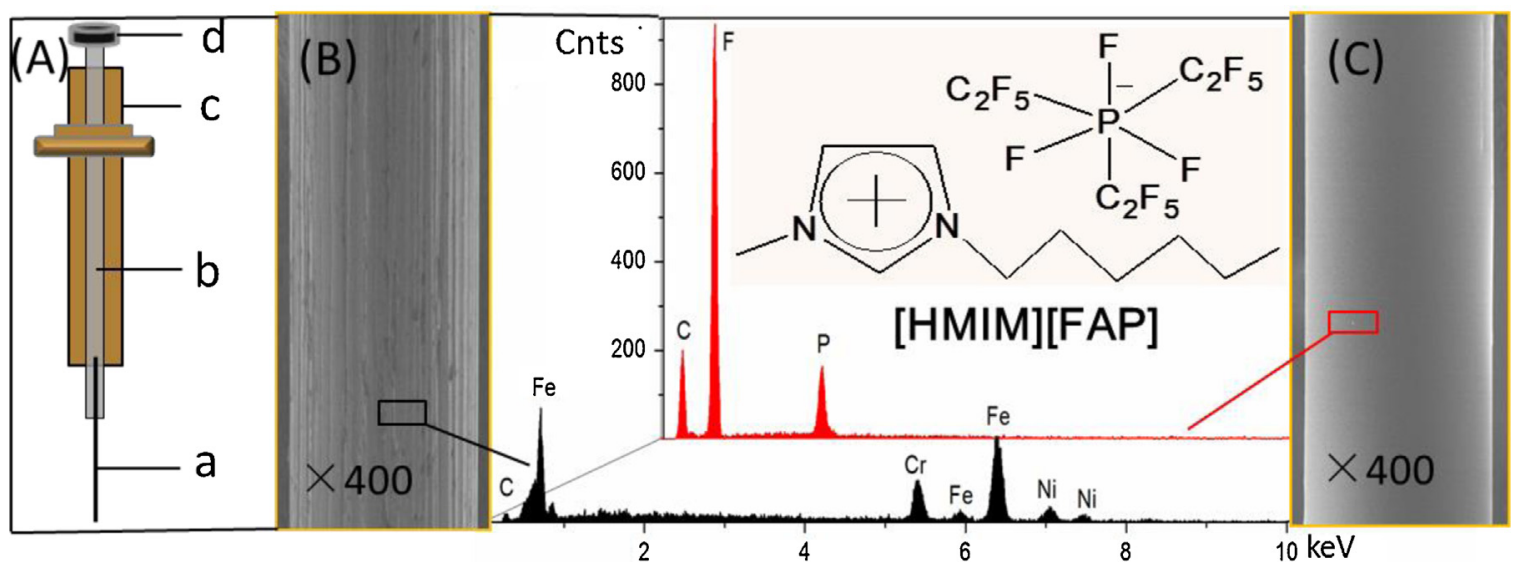

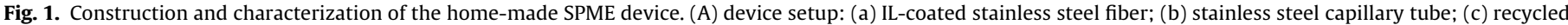

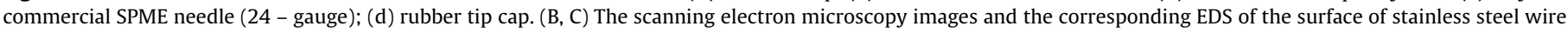
before (B) and after (C) [HMIM][FAP] coating.

based ILs are more hydrophobic and hydrolytically stable. It has been shown that [FAP]-based ILs are immiscible with water; the water uptake for these ILs is more than 10 times less than that of ILs containing the $\left[\mathrm{PF}_{6}\right]^{-}$anion [35]. [FAP]-based ILs have been successfully employed as solvents for liquid-liquid micro-extraction of chlorophenols [26], antidepressant drugs [27], polycyclic aromatic hydrocarbons (PAHs) [36], and ultraviolet filter [37,38]. On the other hand, [FAP]-based ILs like imidazolium based ILs with the [FAP]-anion show decomposition temperature higher than $280^{\circ} \mathrm{C}$ [35]. The ultra-hydrophobicity and high thermal stability of [FAP]based ILs make them excellent alternative coating materials of SPME fiber. However, to our knowledge, the use of [FAP]-based ILs for SPME has yet to be studied.

In this work, IL-based SPME fiber using a new [FAP]-based ILs, 1-hexyl-3- methy limidazolium tris(pentafluoro ethyl) trifluorophosphate ([HMIM][FAP]), as the sorbent coatings was developed for the determination of OPEs in environmental water sample. Several parameters influencing extraction efficiency such as extraction and desorption time, temperature, ionic strength, stirring rate and
pH were optimized. Finally, the proposed IL-based SPME method was coupled to gas chromatography-mass spectrometry (IL-SPME $\mathrm{GC} / \mathrm{MS}$ ) to determine OPEs in environmental water samples.

\section{Experimental}

\subsection{Reagents and materials}

Eleven OPE standards (purities $\geq 98 \%$ ) listed in Table 1 were purchased from Dr. Ehrenstorfer GmbH (Augsburg, Germany). Individual standard stock solutions were prepared at $1.0 \mathrm{mg} \mathrm{mL}^{-1}$ in acetonitrile and working standard solutions were prepared by mixing and diluting individual stock solutions with the same solvent. Calibration solutions, employed during optimization of chromatographic conditions and to validate the performance of the IL-based SPME method, were prepared in dichloromethane. All standard solutions were sealed and stored at $4{ }^{\circ} \mathrm{C}$ in amber glass bottle. [HMIM][FAP] was supplied by Merck (Darmstadt, Germany). [HMIM][FAP], with a structure shown in Fig. 1, has a density

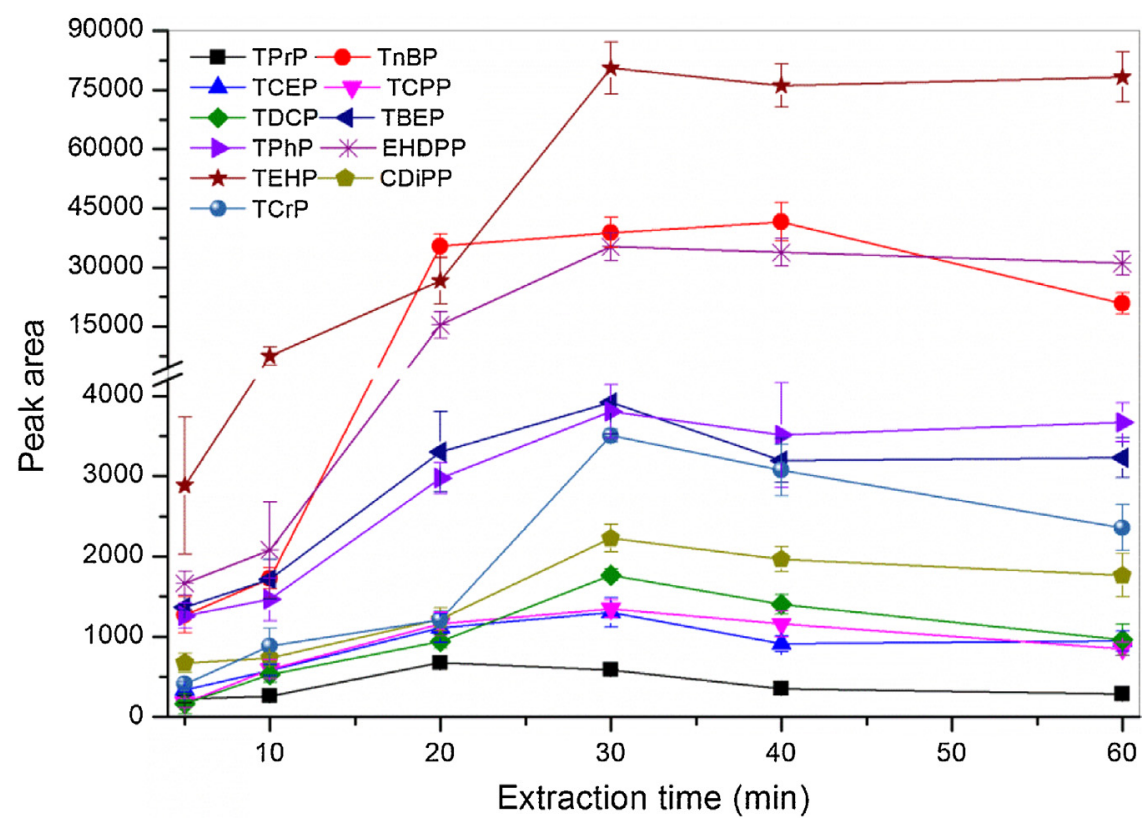

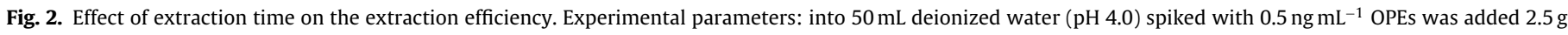
$\mathrm{NaCl}$; extraction temperature $25^{\circ} \mathrm{C}$; stirring rate $450 \mathrm{rpm}$. 
Table 3

Evaluation of possible matrix effects of the proposed SPME method.

\begin{tabular}{|c|c|c|c|c|c|c|c|c|c|}
\hline \multirow[t]{2}{*}{ Compound } & \multicolumn{3}{|l|}{ Tap water } & \multicolumn{3}{|l|}{ STP influent } & \multicolumn{3}{|l|}{ STP effluent } \\
\hline & Blank (ng L ${ }^{-1}$ ) & Recovery $^{\mathrm{a}}(\%)$ & $\mathrm{RSD}(\%)$ & $\operatorname{Blank}\left(\mathrm{ng} \mathrm{L}^{-1}\right)$ & Recovery(\%) & $\mathrm{RSD}(\%)$ & $\operatorname{Blank}\left(\mathrm{ng} \mathrm{L}^{-1}\right)$ & Recovery(\%) & $\operatorname{RSD}(\%)$ \\
\hline TPrP & nd & 88.3 & 6.2 & nd & 96.0 & 9.5 & nd & 94.0 & 8.9 \\
\hline TnBP & $0.6 \pm 0.3$ & 89.4 & 6.3 & $3.8 \pm 1.4$ & 87.2 & 7.7 & $48 \pm 2.8$ & 91.2 & 5.0 \\
\hline TCEP & $10 \pm 1.4$ & 92.2 & 9.2 & $245 \pm 18$ & 82.9 & 6.2 & $250 \pm 37$ & 88.5 & 2.8 \\
\hline ТСРP & nd & 108 & 8.1 & $440 \pm 22$ & 110 & 8.9 & $413 \pm 28$ & 95.0 & 14.6 \\
\hline TDCP & $3.9 \pm 0.7$ & 96.3 & 6.6 & $28 \pm 8.9$ & 112 & 5.3 & $47 \pm 11$ & 97.6 & 5.3 \\
\hline TBEP & nd & 84.0 & 6.0 & $31 \pm 8.2$ & 87.5 & 12.0 & $47 \pm 5.4$ & 85.4 & 8.5 \\
\hline TPhP & nd & 103 & 9.9 & $0.6 \pm 0.1$ & 98.4 & 7.0 & nd & 94.4 & 6.4 \\
\hline EHDPP & nd & 98.3 & 11.0 & nd & 82.1 & 3.1 & nd & 91.2 & 7.9 \\
\hline TEHP & nd & 97.4 & 9.8 & nd & 123 & 4.2 & nd & 82.8 & 7.1 \\
\hline CDiPP & nd & 96.1 & 7.0 & nd & 90.8 & 5.7 & nd & 100 & 9.9 \\
\hline TCrP & nd & 90.2 & 6.2 & nd & 94.4 & 5.5 & nd & 89.6 & 4.2 \\
\hline
\end{tabular}

${ }^{\text {a }}$ Recovery refers the relative spiked recovery at a spiking level of $0.5 \mathrm{ng} \mathrm{mL}{ }^{-1}$, which was calculated by the equation $100 \times\left(C_{\text {found }}-C_{\text {blank }}\right) / C_{\text {initial }}$, in which $C_{\text {found }}$ and $C_{\text {blank }}$

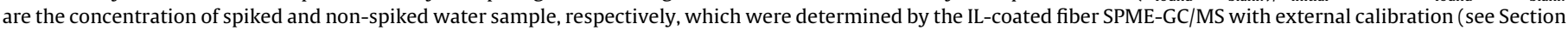
3.3), and $C_{\text {initial }}$ was the spiked concentration $\left(0.5 \mathrm{ng} \mathrm{mL}^{-1}\right)$.

of $1.557 \mathrm{~g} \mathrm{~cm}^{-3}$, a viscosity of $119 \mathrm{cP}$, a decomposition temperature of $290{ }^{\circ} \mathrm{C}$ and a surface tension of $33.2 \mathrm{mN} \mathrm{m}^{-1}[35,36]$. All the organic solvents used were of HPLC grade. Acetonitrile, methanol and $n$-hexane were obtained from Fisher Scientific (UK). Dichloromethane was offered by Dikma Technologies Inc. (USA). Acetone was purchased from J. T. Baker (USA). Hydrochloric acid, sodium hydroxide, sodium chloride were of analytical grade and were all purchased from Sinopharm Chemical Reagent Co., Ltd. (Beijing, China). Deionized water $(18.2 \mathrm{M} \Omega \mathrm{cm})$ was obtained from a Milli-Q water purification system (Millipore, Beldford, MA, USA).

All glassware and magnetic stir bars used in the analytical procedure were cleaned carefully by scrubbing with a brush using hot soapy water, rinsing thoroughly with tap water, followed by ultrasonic cleaning with ethanol, then rinsed with copious amounts of deionized water and dried in the oven at $80^{\circ} \mathrm{C}$, and finally wrapped in aluminum foil. Volumetric flasks were inverted and air dried instead of placing in the oven.

\subsection{Instrumentation}

A 7890A gas chromatograph coupled to $5975 \mathrm{C}$ mass spectrometry (Agilent Technologies, Palo Alto, CA, USA), equipped with split/splitless injector, was employed to quantify the target analytes. An Agilent Technologies HP-5MS capillary column (5\% diphenyl $-95 \%$ dimethyl polysiloxane, $30 \mathrm{~m} \times 0.25 \mathrm{~mm}$ i.d., $0.25 \mu \mathrm{m}$ film thickness) was used as the separation column. The column temperature was programmed as follows: initial oven temperature $55^{\circ} \mathrm{C}$ (held for $2 \mathrm{~min}$ ), then increased to $225^{\circ} \mathrm{C}$ at a rate of $30^{\circ} \mathrm{C} \mathrm{min}-1$, followed by rising to $265^{\circ} \mathrm{C}$ at a rate of $5^{\circ} \mathrm{C} \mathrm{min}^{-1}$, and finally increased to $290^{\circ} \mathrm{C}$ at a rate of $10^{\circ} \mathrm{C} \mathrm{min}^{-1}$ (held for $5 \mathrm{~min}$ ). The splitless injector was set at $200^{\circ} \mathrm{C}$ and the injected volume was $1 \mu \mathrm{L}$. Helium (99.999\%) was used as carrier gas at a flow rate of $0.8 \mathrm{~mL} \mathrm{~min}^{-1}$ with constant flow mode. The solvent delay time was set as $4 \mathrm{~min}$. The mass spectrometric detection was operated in scan mode from $m / z$ 50-550 with electron impact (EI) energy of $70 \mathrm{eV}$. The MS quard and ion source temperature was $180^{\circ} \mathrm{C}$ and $280^{\circ} \mathrm{C}$, respectively. Selective ion monitoring (SIM) was used to quantify the target compounds. Quantification ions and qualification ions of OPEs were listed in Table 1.

\subsection{Preparation of IL-based SPME fiber}

Laboratory-made simple SPME device (Fig. 1A) was modified from a manual SPME fiber holder. The stainless steel capillary tube ( $400 \mu \mathrm{m}$ o.d., $200 \mu \mathrm{m}$ i.d., ca. $10 \mathrm{~cm}$ of the length) was inserted into the recycled commercial SPME 24-gauge needle as the plunger. The plunger can be extended from the needle or retracted back into the needle as needed. The stainless steel wire, which has being rubbed to a diameter of $0.10-0.15 \mathrm{~mm}$ with fine sand paper, was inserted into the plunger and fixed with polyacrylate adhesive at an elevated temperature $\left(180^{\circ} \mathrm{C}\right)$, and making sure that $1 \mathrm{~cm}$ segment of stainless steel wire exposed to outside the plunger as the fiber for coating and extraction.

Prior to being coated, the stainless steel wire was mechanically rubbed with a fine sand paper to get a rough and porous surface. Then the $1 \mathrm{~cm}$ segment fiber was washed successively with $0.1 \mathrm{M}$ sodium hydroxide, $0.1 \mathrm{M}$ hydrochloric acid, methanol, acetone and deionized water, follow by dried in an oven over a relative wide range of temperature $\left(50^{\circ} \mathrm{C}-130^{\circ} \mathrm{C}\right)$. The pre-treated stainless steel fiber was perpendicularly immersed into the IL coating solution for 3 min and then slowly pulled out to obtain smooth IL coatings. To obtain a coating of adequate thickness for guaranteeing the excellent sensitivity, repeatability and lifespan of the coating, the coating process was repeated five times. Subsequently, the fiber was conditioned in the GC inlet under a gentle stream of helium (He) at $230^{\circ} \mathrm{C}$ for $30 \mathrm{~min}$. Prior to performing extractions, the fiber was also reconditioned for approximately $10 \mathrm{~min}$ at the same temperature to eliminate the volatile impurities.

Surface morphology and elemental analysis of the developed IL-coated fiber was performed by using a Hitachi S-3000 N scanning electron microscope (SEM) equipped with energy dispersive spectrometer (EDS) (Tokyo, Japan). The amounts of ILs adsorbed on the stainless steel fiber was determined by high performance liquid chromatography with a UV detector (HPLC-UV) after desorbing into acetonitrile by sonication (see details in Supplementary materials).

\subsection{SPME procedure}

All extractions were conducted in the direct immersion (DI) - SPME mode, using $50 \mathrm{~mL}$ extraction conical flasks containing $50 \mathrm{~mL}$ of the aqueous working solution. Unless otherwise stated, the $\mathrm{pH}$ of the sample was adjusted to $\mathrm{pH} 4.0$ by adding $1.0 \mathrm{M} \mathrm{HCl}$ or $1.0 \mathrm{M} \mathrm{NaOH}$ solution dropwise. The flask was quickly sealed with aluminum foil cap and rubber cap sequentially after adding $2.5 \mathrm{~g} \mathrm{NaCl}$ and introducing a $3.0 \mathrm{~cm}$ length polytetrafluoroethylene (PTFE) coated magnetic stir bar. To perform SPME, the needle of the SPME device was introduced into the extraction conical flask, and then the $1 \mathrm{~cm}$ length of IL-coated fiber was pushed to completely immerse into sample solution. Subsequently, the flask was placed in a thermostatic water bath setting at $25^{\circ} \mathrm{C}$. The stirring rate was set at $450 \mathrm{rpm}$ for $30 \mathrm{~min}$. After extracting for a prescribed time, the fiber was withdrawn back into the needle of SPME device and immediately introduced into the $\mathrm{GC}$ injector port $\left(200^{\circ} \mathrm{C}\right)$ for thermal desorption and subsequent analysis. 


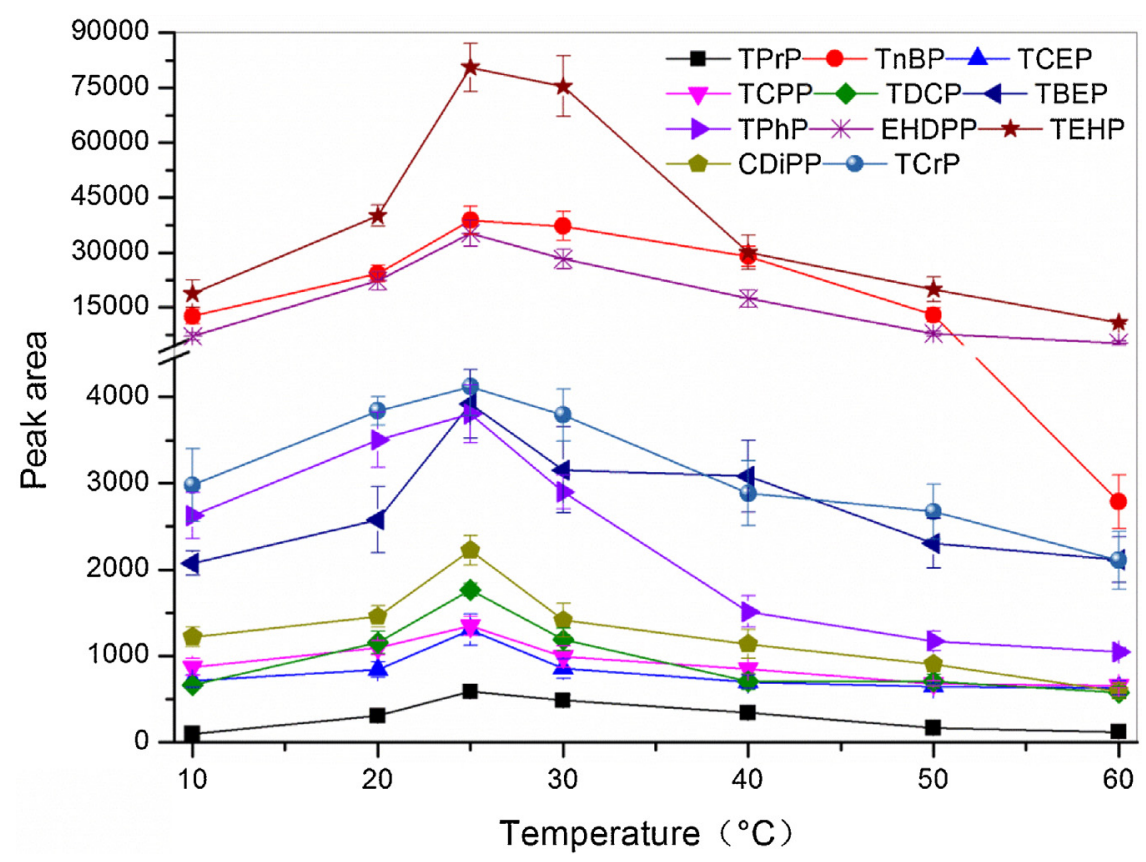

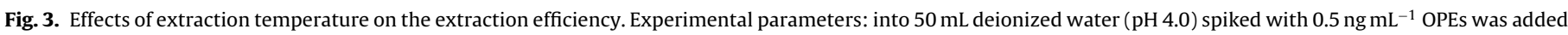
$2.5 \mathrm{~g} \mathrm{NaCl}$; extraction time $30 \mathrm{~min}$; stirring rate $450 \mathrm{rpm}$.

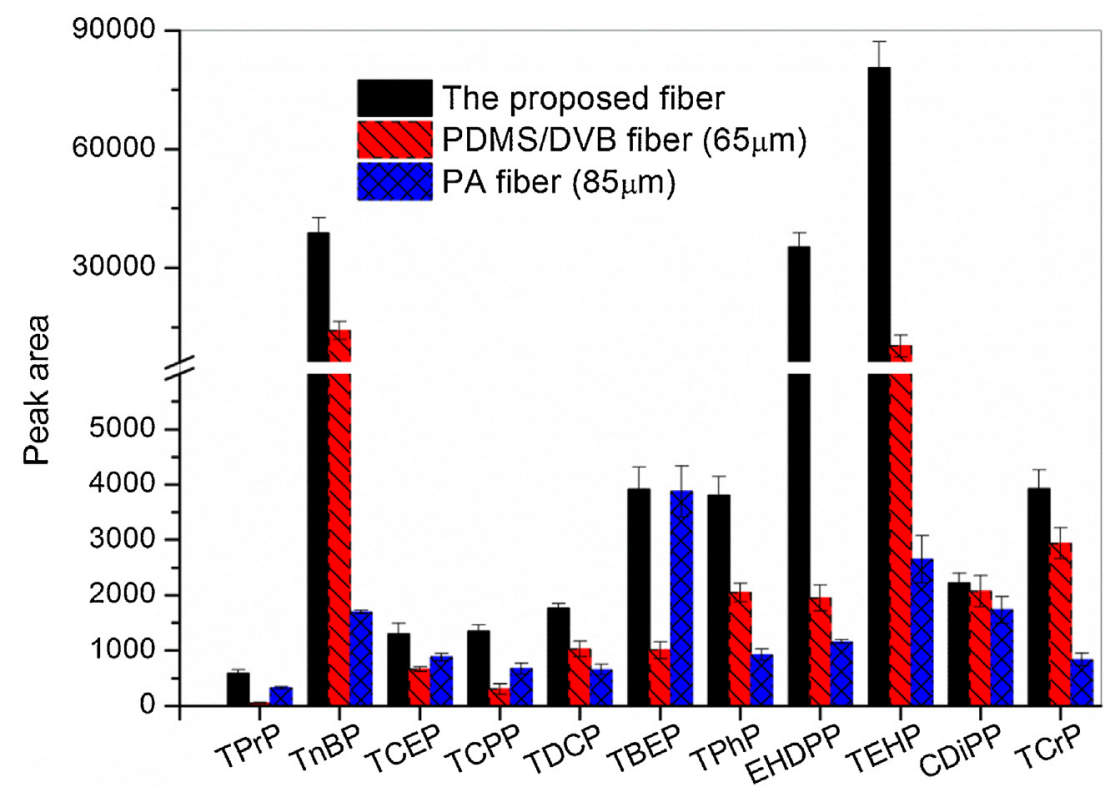

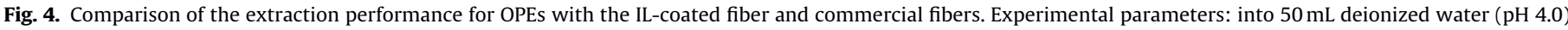
spiked with $0.5 \mathrm{ng} \mathrm{mL}^{-1}$ OPEs was added $2.5 \mathrm{~g} \mathrm{NaCl}$; extraction time $30 \mathrm{~min}$; extraction temperature $25^{\circ} \mathrm{C}$; stirring rate $450 \mathrm{rpm}$.

\subsection{Sample collection}

Three environmental water samples including tap water, influent and effluent of a STP were analyzed in the present study. Laboratory tap water was collected from a water tap after continual flow for at least $10 \mathrm{~min}$. The influent and effluent of municipal sewage water sample were taken from Qinghe sewage treatment plant, located in the northwest of Beijing. These samples were filtered through Whatman GF/C glass fiber filters (Whatman Plc., Maidstone, UK) to remove particulate matter and stored in amber glass containers at $4{ }^{\circ} \mathrm{C}$.

\section{Results and discussion}

\subsection{Preparation and characterization of the IL-coated fiber}

Fig. 1 shows the SEM images of the stainless steel wire before and after the coating of IL. Before the coating of IL the surface of the rubbed stainless steel wire was rough and porous, benefiting for the coating of IL. The stainless steel wire became smooth after coating, suggesting the IL was coated on the surface. EDS analysis was also performed to verify the coating of IL. While the bare stainless steel wire shows peaks corresponding to the presence of $\mathrm{Fe}, \mathrm{Cr}$ and $\mathrm{Ni}$ (Fig. 1B), only the emission lines of $\mathrm{C}, \mathrm{P}$ and $\mathrm{F}$ appear for the IL coated fiber (Fig. 1C), indicating the complete coverage 
Table 4

Levels of organophosphate esters in real water samples ( $\mathrm{ng} \mathrm{L}^{-1}$, mean $\pm \mathrm{SD}, \mathrm{n}=3$ ) determined by IL-SPME GC-MS method and SPE UPLC-MS/MS method (ref. method).

\begin{tabular}{|c|c|c|c|c|c|c|}
\hline \multirow[t]{2}{*}{ Compound } & \multicolumn{2}{|c|}{ Tap water } & \multicolumn{2}{|c|}{ STP influent } & \multicolumn{2}{|c|}{ STP effluent } \\
\hline & A & B & A & B & A & B \\
\hline TPrP & $\mathrm{nd}^{\mathrm{a}}$ & nd & nd & nd & nd & nd \\
\hline TnBP & $0.6 \pm 0.3$ & $0.5 \pm 0.02$ & $3.8 \pm 1.4$ & $5.2 \pm 0.8$ & $48 \pm 2.8$ & $48 \pm 1.2$ \\
\hline TCEP & $10 \pm 1.4$ & $13 \pm 1.7$ & $245 \pm 18$ & $251 \pm 37$ & $250 \pm 37$ & $221 \pm 26$ \\
\hline ТСРP & nd & nd & $440 \pm 22$ & $451 \pm 11$ & $413 \pm 28$ & $400 \pm 16$ \\
\hline TDCP & $3.9 \pm 0.7$ & $2.2 \pm 1.9$ & $28 \pm 8.9$ & $25 \pm 8.9$ & $47 \pm 11$ & $44 \pm 12$ \\
\hline TBEP & nd & nd & $31 \pm 8.2$ & $37 \pm 3.9$ & $47 \pm 5.4$ & $40 \pm 4.2$ \\
\hline TPhP & nd & nd & $0.6 \pm 0.1$ & nd & nd & nd \\
\hline EHDPP & nd & nd & nd & nd & nd & nd \\
\hline TEHP & nd & nd & nd & nd & nd & nd \\
\hline CDiPP & nd & nd & nd & nd & nd & nd \\
\hline $\mathrm{TCrP}$ & nd & nd & nd & nd & nd & nd \\
\hline
\end{tabular}

A. this method B. ref. method.

a nd: not detected.

of the stainless steel wire by IL [HMIM][FAP]. It is difficult to measure the coating thickness directly by SEM due to the coating film is still in a liquid form. The amount of ILs adsorbed on the stainless steel wire, determined by HPLC-UV after desorbing into acetonitrile by sonication (see details in Supplementary Materials), was $0.1130 \pm 0.005 \mu \mathrm{L}$.

\subsection{Optimization of the extraction conditions by IL-coated SPME}

To obtain the highest extraction efficiency, several experimental parameters that affect the extraction efficiency, including extraction time, temperature, stirring rate, ionic strength and $\mathrm{pH}$ value were optimized with working solutions at a spiking level of $0.5 \mathrm{ng} \mathrm{mL} \mathrm{m}^{-1}$ each of the OPEs.

\subsubsection{Desorption time}

Proper desorption time must be chosen to release analytes adequately from the SPME fiber. For all target analytes, maximum desorption was achieved within $5 \mathrm{~min}$. In order to avoid the memory effects, $10 \mathrm{~min}$ desorption time was adopted. The analytes carryover was $<1 \%$, which was periodically checked by reinserting the fiber into a GC injection port for an additional 5 min following the previous desorption step.

\subsubsection{Effect of extraction time}

The extraction profiles of OPEs by the developed SPME fiber were achieved to optimize the extraction time. As shown in Fig. 2, significant increases of analytes responses were observed with increase of extraction time from 5 to $30 \mathrm{~min}$. After $30 \mathrm{~min}$, the extraction efficiency reached a plateau or decreased slightly with the prolonged extraction time, which might be caused by the loss of the analytes due to their evaporation to the headspace. Therefore, 30 min was employed for further studies.

\subsubsection{Effect of extraction temperature}

Fig. 3 shows the influence of the extraction temperature on the extraction efficiency of OPEs. For all the studied OPEs, the extraction efficiency increased with temperature to $25^{\circ} \mathrm{C}$, and decreased with the further increase of temperature. In general, higher extraction efficiency can be expected by increasing the temperature. However, adsorption is generally an exothermic process; elevated temperature would reduce the absorptivity of the coating of SPME fiber in aqueous solutions. It was observed that increasing temperature above ambient can cause loss of analytes in bulk solution due to evaporation of target compounds to the headspace. Furthermore, high temperature can also lead to a decrease of the partition coefficient [34]. Thus, the following experiments were carried out at ambient temperature $\left(25^{\circ} \mathrm{C}\right)$.

\subsubsection{Effect of stirring rate}

Mass diffusion was recognized as the rate-determining step that may retard the process of reaching the adsorption equilibrium. In order to accelerate the mass transfer velocity from bulk solution to coating fiber and shorten extraction time, stirring was commonly used to speed up the extraction. Fig. S1 shows that the extraction efficiency markedly increased with the increasing of stirring rates in the range of $0-450 \mathrm{rpm}$. However, stirring at $600 \mathrm{rpm}$ made the stirring bar spinning unevenly, which produced air bubbles that attached to fiber coating and therefore results in an inferior reproducibility (relative standard deviation, RSD $=16.0-22.7 \%$ ). Therefore, subsequent experiments were performed at $450 \mathrm{rpm}$.

\subsubsection{Effect of ionic strength}

Due to the salting-out effect for hydrophobic compounds, it is a common practice to add salt to aqueous samples to increase the ionic strength of the sample solution and enhance partition of organic analytes between fiber coating and aqueous phase $[23,34]$. The effect of salt was examined by adding $\mathrm{NaCl}$ in the range of $0-20 \%(w / v)$. As shown in Fig. S2, an obviously positive effect on extraction efficiency of OPEs was observed in aqueous phase with the increase of $\mathrm{NaCl}$ content to $5 \%(\mathrm{w} / \mathrm{v})$. However, further increase of $\mathrm{NaCl}$ content gave rise to decreased extraction efficiency, which was attributed to the increased sample viscosity and therefore a decreased diffusion rate of the analytes from the bulk solution to the coating fiber. Therefore, $5 \%$ of $\mathrm{NaCl}$ was selected in further experiments.

\subsubsection{Effect of $p H$}

The sample $\mathrm{pH}$ could change molecular format of analytes and thus affect the partition coefficient of analytes between the bulk solution and fiber coatings. Moreover, the protonation and deprotonation of nitrogen atoms in the imidazole group of [HMIM][FAP] are largely $\mathrm{pH}$-dependent, which can influence extraction efficiency due to the change of hydrophobicity of sorbent coatings. Fig. S3 shows the effect of sample solution $\mathrm{pH}$ on the extraction efficiency. The extraction efficiency increased with sample $\mathrm{pH}$ value from 3.0 to 4.0 , and then slightly decreased with the increasing of $\mathrm{pH}$ value from 4.0 to 9.0, but the extraction efficiency decreased sharply when sample solution $\mathrm{pH}$ increased continuously to 12.0 . The extraction efficiency variation trend with the variation of sample $\mathrm{pH}$ values may be explained as follows: at low sample $\mathrm{pH}$ range, the increase of sample $\mathrm{pH}$ gave rise to deprotonation of nitrogen atoms in the imidazole group [39], and therefore higher hydrophobicity of IL and extraction efficiency. With the increased of $\mathrm{pH}$ in the range of 4.0-9.0, the extraction efficiencies of OPEs slightly decreased, except for TnBP and TPhP that decreased significantly 
for unclear reasons. The significant decrease of extraction efficiency of most OPEs with $\mathrm{pH}$ in the range of 9.0-12.0 might be ascribed to the hydrolysis of OPEs. According to the results, an optimum $\mathrm{pH}$ value of 4.0 was utilized in the further experiments.

\subsection{Evaluation of the method performance}

The analytical performance of the developed fiber was evaluated in terms of calibration curves, linear range, sensitivity, precision and reproducibility under the above optimized conditions. The linearity was evaluated by extracting deionized water spiked with 11 OPEs at 7 different concentration levels. For each level, triplicate extrations were conducted under optimal conditions. As tabulated in Table 2, linearity was established over the concentration range of $0.05-50 \mathrm{ng} \mathrm{mL}^{-1}$ for all analytes except for TCEP and TCPP (0.05-5 $\left.\mathrm{ng} \mathrm{mL} \mathrm{mL}^{-1}\right)$ with correlation coefficient $\left(\mathrm{R}^{2}\right)$ ranging from 0.9156 to 0.9999 . Limits of detection (LODs) and limits of quantitation (LOQs) of the method, established using the signal to noise $(\mathrm{S} / \mathrm{N})$ ratio of 3 and 10 , ranged from 0.13 to $7.4 \mathrm{ng} \mathrm{L}^{-1}$ and $0.5-24 \mathrm{ng} \mathrm{L}^{-1}$, respectively. The developed IL-based fiber showed respectable enrichment factors for all target analytes, varying from 168 for TPrP to 2603 for EHDPP (Table 2).

The single fiber repeatability (expressed as RSD) for 7 replicates analysis at the spiking level of $0.5 \mathrm{ng} \mathrm{mL}^{-1}$ were in the range of $1.2 \%-15 \%$. The fiber-to-fiber reproducibility of proposed IL-coated SPME fiber, tested by determining the RSDs of three parallel fabricated fibers in analysis of $0.5 \mathrm{ng} \mathrm{mL}^{-1}$ OPEs, ranged from $5.5 \%$ to $16 \%$. The durability of the developed SPME fiber was tested by successive analysis of a standard solution containing $0.5 \mathrm{ng} \mathrm{mL}^{-1}$ each of the OPEs using one single fiber, and no reduction of the extraction efficiency was observed after 65 extractions were performed (RSD $\leq 18.3 \%$, see Fig. S4).

For further evaluating the performance of the proposed fiber, the analytical performance was compared with those of the previously reported ILs-based fibers for determination of OPEs in aqueous samples (Table S1), which indicated the [HMIM][FAP] coated fiber offered the best performance. The analytical performance of the proposed IL-based fiber was also compared with two commercial SPME fibers (i.e. $65 \mu \mathrm{m}$ PDMS-DVB and $85 \mu \mathrm{m}$ PA) using the direct immersion extraction mode and the same extraction conditions as that for the developed fiber. As illustrated in Fig. 4, the IL-based fiber showed much higher extraction efficiency than the commercial fibers (both PDMS-DVB and PA) for all OPEs studied, and a comparable blank bleeding of thermal desorption with PDMS-DVB fiber and much less than PA fiber (Fig. S5). The superior performance of ILbased fiber might be attributed to the inherent excellent extraction capability of [FAP]-based ILs for organic compounds, and especially for nonpolar compounds [36].

\subsection{Evaluation of matrix effect}

Extraction yield by direct immersion SPME was sample dependent. The matrix effects were investigated by spiking each of the 11 studied OPEs at a level of $0.5 \mathrm{ng} \mathrm{mL}^{-1}$ in tap water, influent and effluent of sewage treatment plant, respectively. The analytes recoveries of the three different real water samples were listed in Table 3. Recoveries ranged from $84.0-108 \%, 82.1-123 \%$ and $82.8-100 \%$ for tap water, influent of STP, effluent of STP, respectively. These results clearly indicate that our proposed SPME fiber not only provide exceptional extraction efficiency and selectivity but also are tolerant to matrixes of real water samples.

\subsection{Application to real water sample analysis}

Real samples including tap water, influent and effluent of sewage treatment plant were analyzed by the pro- posed method. SPE coupled with ultra-performance liquid chromatography-tandem mass spectrometry (UPLC-MS/MS) [17] was also used to evaluate the accuracy of the proposed method, and the results were listed in Table 4. Pair-sample t-test showed that for all the samples OPEs concentration determined by the two methods are not significantly different $(p>0.05)$ at the $95 \%$ confidence level.

\section{Conclusions}

In the present study, an ultra-hydrophobic IL [HMIM][FAP]based SPME fiber was for the first time developed for the determination of OPEs in water samples. The developed [HMIM][FAP]-based SPME fiber exhibits high extraction capacity, excellent mechanical stability, low-cost, satisfied single fiber repeatability and fiber-to-fiber reproducibility for most OPEs, including TCEP and TEHP that are always recalcitrant in conventional pretreatment procedure. In addition, the proposed method showed good recoveries and RSDs for analysis of OPEs in the real water samples. Furthermore, the proposed [HMIM][FAP]based SPME coating showed long-term stability, without loss of the IL-coatings and reduction of extraction efficiency after more than 65 extraction cycles. Overall, owing to the FAP-based ILs exhibit extremely high hydrophobicity and low hydrolysity, they are perfect candidates of SPME fiber stationary phase coatings for extraction analytes from aqueous matrixes using direct immersion SPME.

\section{Acknowledgements}

This study was financially supported by the High-Tech Research and Development Program of China (2013AA065201), the Strategic Priority Research Program of the Chinese Academy of Sciences (XDB14020101), and the National Natural Science Foundation of China (21321004).

\section{Appendix A. Supplementary data}

Supplementary data associated with this article can be found, in the online version, at http://dx.doi.org/10.1016/j.chroma.2016.04. 021.

\section{References}

[1] J. Andresen, K. Bester, Elimination of organophosphate ester flame retardants and plasticizers in drinking water purification, Water Res. 40 (2006) 621-629.

[2] R.M. Wang, J.H. Tang, Z.Y. Xie, W.Y. Mi, Y.J. Chen, H. Wolschke, C.G. Tian, X.H. Pan, Y.M. Luo, R. Ebinghaus, Occurrence and spatial distribution of organophosphate ester flame retardants and plasticizers in 40 rivers draining into the Bohai Sea, north China, Environ. Pollut. 198 (2015) 172-178.

[3] J. Meyer, K. Bester, Organophosphate flame retardants and plasticisers in wastewater treatment plants, J. Environ. Monit. 6 (2004) 599-605.

[4] S. Mizouchi, M. Ichiba, H. Takigami, N. Kajiwara, T. Takamuku, T. Miyajima, H. Kodama, T. Someya, D. Ueno, Exposure assessment of organophosphorus and organobromine flame retardants via indoor dust from elementary schools and domestic houses, Chemosphere 123 (2015) 17-25.

[5] F.X. Yang, J.J. Ding, W. Huang, W. Xie, W.P. Liu, Particle size-specific distributions and preliminary exposure assessments of organophosphate flame retardants in office air particulate matter, Environ. Sci. Technol. 48 (2014) 63-70.

[6] S.C. Lai, Z.Y. Xie, T.L. Song, J.H. Tang, Y.Y. Zhang, W.Y. Mi, J.H. Peng, Y. Zhao, S.C. Zou, R. Ebinghaus, Occurrence and dry deposition of organophosphate esters in atmospheric particles over the northern South China Sea, Chemosphere 127 (2015) 195-200.

[7] T. Reemtsma, J.B. Quintana, R. Rodil, M. García-López, I. Rodríguez, Organophosphorus flame retardants and plasticizers in water and air I. Occurrence and fate, TrAC-Trend Anal. Chem. 27 (2008) 727-737.

[8] J. Li, N. Yu, B. Zhang, L. Jin, M. Li, M. Hu, X. Zhang, S. Wei, H. Yu, Occurrence of organophosphate flame retardants in drinking water from China, Water Res. 54 (2014) 53-61. 
[9] E. Martínez-Carballo, C. González-Barreiro, A. Sitka, S. Scharf, O. Gans, Determination of selected organophosphate esters in the aquatic environment of Austria, Sci. Total Environ. 388 (2007) 290-299.

[10] A.M. Sundkvist, U. Olofsson, P. Haglund, Organophosphorus flame retardants and plasticizers in marine and fresh water biota and in human milk, J. Environ. Monit. 12 (2010) 943-951.

[11] J.W. Kim, T. Isobe, K.H. Chang, A. Amano, R.H. Maneja, P.B. Zamora, F.P. Siringan, S. Tanabe, Levels and distribution of organophosphorus flame retardants and plasticizers in fishes from Manila Bay, the Philippines, Environ. Pollut. 159 (2011) 3653-3659.

[12] E. Cequier, A.K. Sakhi, R.M. Marcé, G. Becher, C. Thomsen, Human exposure pathways to organophosphate triesters-a biomonitoring study of mother-child pairs, Environ. Int. 75 (2015) 159-165.

[13] P.D. Noyes, D.E. Haggard, G.D. Gonnerman, R.L. Tanguay, Advanced morphological-behavioral test platform reveals neurodevelopmental defects in embryonic zebrafish exposed to comprehensive suite of halogenated and organophosphate flame retardants, Toxicol. Sci. 145 (2015) 177-195

[14] F.Y. Song, R.R. Kou, C.S. Zou, Y. Gao, T. Zeng, K.Q. Xie, Involvement of autophagy in tri-ortho-cresyl phosphate-induced delayed neuropathy in hens, Neurochem. Int. 64 (2014) 1-8.

[15] I. Rodríguez, F. Calvo, J.B. Quintana, E. Rubí, R. Rodil, R. Cela, Suitability of solid-phase microextraction for the determination of organophosphate flame retardants and plasticizers in water samples, J. Chromatogr. A 1108 (2006) $158-165$.

[16] T.L.L. Teo, J.A. McDonald, H.M. Coleman, S.J. Khan, Analysis of organophosphate flame retardants and plasticisers in water by isotope dilution gas chromatography-electron ionisation tandem mass spectrometry, Talanta 143 (2015) 114-120.

[17] K. Liang, Y.M. Niu, J.F. Liu, Determination of 14 organophosphate ester flame retardants in wastewater by UPLC-MS/MS, Environ. Chem. 33 (2014) $1681-1685$

[18] T.K. Choudhury, K.O. Gerhardt, T.P. Mawhinney, Solid-phase microextraction of nitrogen- and phosphorus-containing pesticides from water and gas chromatographic analysis, Environ. Sci. Technol. 30 (1996) 3259-3265.

[19] G. Vas, K. Vékey, Solid-phase microextraction: a powerful sample preparation tool prior to mass spectrometric analysis, J. Mass Spectrom. 39 (2004) 233-254.

[20] D.W. Potter, J. Pawliszyn, Rapid determination of polyaromatic hydrocarbons and polychlorinated biphenyls in water using solid-phase microextraction and GC/MS, Environ. Sci. Technol. 28 (1994) 298-305.

[21] C.L. Arthur, J. Pawliszyn, Solid phase microextraction with thermal desorption using fused silica optical fibers, Anal. Chem. 62 (1990) 2145-2148.

[22] Z.Y. Zhang, M.J. Yang, J. Pawliszyn, Solid-phase microextraction. A solvent-free alternative for sample preparation, Anal. Chem. 66 (1994) 844A-853A.

[23] D. Djozan, B. Ebrahimi, M. Mahkam, M.A. Farajzadeh, Evaluation of a new method for chemical coating of aluminum wire with molecularly imprinted polymer layer. Application for the fabrication of triazines selective solid-phase microextraction fiber, Anal. Chim. Acta 674 (2010) 40-48.

[24] H. Kataoka, H.L. Lord, J. Pawliszyn, Applications of solid-phase microextraction in food analysis, J. Chromatogr. A 880 (2000) 35-62.

[25] Y.C. Tsao, Y.C. Wang, S.F. Wu, W.H. Ding, Microwave-assisted headspace solid-phase microextraction for the rapid determination of organophosphate esters in aqueous samples by gas chromatography-mass spectrometry, Talanta 84 (2011) 406-410.
[26] D.D. Ge, H.K. Lee, Ultra-hydrophobic ionic liquid 1-hexyl-3-methylimidazolium tris(pentafluoroethyl)trifluorophosphate supported hollow-fiber membrane liquid-liquid-liquid microextraction of chlorophenols, Talanta 132 (2015) 132-136.

[27] D.D. Ge, H.K. Lee, Ionic liquid based dispersive liquid liquid microextraction coupled with micro-solid phase extraction of antidepressant drugs from environmental water samples, J. Chromatogr. A 1317 (2013) 217-222.

[28] M. Amde, J.F. Liu, L. Pang, Environmental application, fate, effects, and concerns of ionic liquids: a review, Environ. Sci. Technol. 49 (2015) $12611-12627$.

[29] J.F. Liu, G.B. Jiang, Y.G. Chi, Y.Q. Cai, Q.X. Zhou, J.T. Hu, Use of ionic liquids for liquid-phase microextraction of polycyclic aromatic hydrocarbons, Anal. Chem. 75 (2003) 5870-5876

[30] J.F. Liu, Y.G. Chi, G.B. Jiang, C. Tai, J.F. Peng, J. Hu, Ionic liquid-based liquid-phase microextraction, a new sample enrichment procedure for liquid chromatography, J. Chromatogr. A 1026 (2004) 143-147.

[31] H.Y. Kang, Y.L. Mao, X.L. Wang, Y. Zhang, J.F. Wu, H.Q. Wang, Disposable ionic liquid-coated etched stainless steel fiber for headspace solid-phase microextraction of organophosphorus flame retardants from water samples, RSC Adv. 5 (2015) 41934-41940.

[32] M. Cui, J. Qiu, Z. Li, M. He, M. Jin, J. Kim, M. Quinto, D. Li, An etched stainless steel wire/ionic liquid-solid phase microextraction technique for the determination of alkylphenols in river water, Talanta 132 (2015) 564-571.

[33] J.F. Liu, N. Li, G.B. Jiang, J.M. Liu, J.Å. Jönsson, M.J. Wen, Disposable ionic liquid coating for headspace solid-phase microextraction of benzene toluene, ethylbenzene, and xylenes in paints followed by gas chromatography-flame ionization detection, J. Chromatogr. A 1066 (2005) 27-32.

[34] Z.Q. Gao, Y.H. Deng, X.B. Hu, S.G. Yang, C. Sun, H. He, Determination of organophosphate esters in water samples using an ionic liquid-based sol-gel fiber for headspace solid-phase microextraction coupled to gas chromatography-flame photometric detector, J. Chromatogr. A 1300 (2013) $141-150$.

[35] N.V. Ignat'ev, U. Welz-Biermann, A. Kucheryna, G. Bissky, H. Willner, New ionic liquids with tris(perfluoroalkyl)trifluorophosphate (FAP) anions, J. Fluor. Chem. 126 (2005) 1150-1159.

[36] C. Yao, W.R. Pitner, J.L. Anderson, Ionic liquids containing the tris(pentafluoroethyl)trifluorophosphate anion: a new class of highly selective and ultra hydrophobic solvents for the extraction of polycyclic aromatic hydrocarbons using single drop microextraction, Anal. Chem. 81 (2009) 5054-5063

[37] D.D. Ge, H.K. Lee, Ionic liquid based hollow fiber supported liquid phase microextraction of ultraviolet filters, J. Chromatogr. A 1229 (2012) 1-5.

[38] Y.F. Zhang, H.K. Lee, Ionic liquid-based ultrasound-assisted dispersive liquid-liquid microextraction followed high-performance liquid chromatography for the determination of ultraviolet filters in environmental water samples, Anal. Chim. Acta 750 (2012) 120-126.

[39] M. Mei, J. Yu, X. Huang, H. Li, L. Lin, D. Yuan, Monitoring of selected estrogen mimics in complicated samples using polymeric ionic liquid-based multiple monolithic fiber solid-phase microextraction combined with high-performance liquid chromatography, J. Chromatogr. A 1385 (2015) 12-19.

[40] I. van der Veen, J. de Boer, Phosphorus flame retardants: properties, production, environmental occurrence, toxicity and analysis, Chemosphere 88 (2012) 1119-1153. 